\title{
Incidence and risk factors of surgical site infections and related antibiotic resistance in Freetown, Sierra Leone: a prospective cohort study
}

Sulaiman Lakoh ${ }^{1,2,7^{*+}}$ (1), Le Yi ${ }^{3 \dagger}$, Stephen Sevalie ${ }^{1,4}$, Xuejun Guo ${ }^{3 *}$, Olukemi Adekanmbi ${ }^{5,6}$, Isaac O. Smalle ${ }^{1,2}$, Nathaniel Williams², Umu Barrie ${ }^{7}$, Celesis Koroma ${ }^{4}$, Yongkun Zhao ${ }^{3}$, Matilda N. Kamara', Constance Cummings-John ${ }^{1,2}$, Darlinda F. Jiba², Enanga Sonia Namanaga², Betsy Deen², Juling Zhang ${ }^{8}$, Anna Maruta ${ }^{9}$, Christiana Kallon ${ }^{2}$, Peng Liu ${ }^{10}$, Haja Ramatulai Wurie ${ }^{1}$, Joseph Sam Kanu ${ }^{1,2}$, Gibrilla F. Deen ${ }^{1,2}$, Mohamed Samai ${ }^{1,2}$, Foday Sahr ${ }^{1,4}$ and Emmanuel Firima ${ }^{11,12,13,14}$

\begin{abstract}
Background: There is limited information on surgical site infections (SSI) and the related antibiotic resistance needed to guide their management and prevention in Sierra Leone. In this study, we aimed to establish the incidence and risk factors of SSI and the related antibiotic resistance among adults attending a tertiary hospital, and a secondary health facility in Freetown, Sierra Leone.

Methods: This is a prospective cohort study designed to collect data from adult (18 years or older) patients who attended elective and emergency surgeries at two hospitals in Freetown between February and July, 2021. Data analysis was done using STATA version 16.

Results: Of 338 patients, 245 (72.5\%) and 93 (27.5\%) had their surgeries at the tertiary and secondary hospitals, respectively. Many were males 192 (56.8\%), less than 35 years 164 (48.5\%), and 39 (11.5\%) developed an SSI. Of the 39 patients who acquired an SSI, 7 (17.9\%) and 32 (82.1\%) had their surgeries at the secondary and tertiary hospitals, respectively. The incidence of SSI is higher in contaminated 17 (43.6\%) than in clean-contaminated 12 (30.8\%) and clean 10 (25.6\%) wounds. Wound swabs were collected in 29 (74.4\%) patients, of which 18 (62.1\%) had bacterial growth. In total, 49 isolates of 14 different bacteria including gram-negative 41 (83.7\%) and gram-positive 8 (16.3\%) isolates were identified. Of these, 32 (65.3\%) were Enterobacteriaceae, 9 (18.4\%) were Non-fermenting gram-negative bacilli and 10 (12.2\%) were Enterococci. The most common isolates were Escherichia coli (12, 24.5\%), Klebsiella pneumoniae (10, 20.4\%), Acinetobacter baumannii (5, 10.2\%), Klebsiella oxytoca (4, 8.2\%) and Enterococcus faecalis (4, 8.2\%). The Enterobacteriaceae were either resistance to carbapenems (4, 8.2\%) or were extended-spectrum beta-lactamase (ESBL)
\end{abstract}

\footnotetext{
*Correspondence: lakoh2009@gmial.com; xuejung@yahoo.com

†Sulaiman Lakoh and Le Yi have contributed equally to this work and

should be regarded as co-first authors

${ }^{1}$ College of Medicine and Allied Health Sciences, University of Sierra

Leone, Freetown, Sierra Leone

${ }^{3}$ Changchun Veterinary Research Institute, Chinese Academy

of Agricultural Sciences, Changchun 130000, China

Full list of author information is available at the end of the article
}

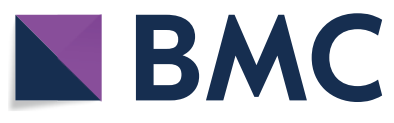

(c) The Author(s) 2022. Open Access This article is licensed under a Creative Commons Attribution 4.0 International License, which permits use, sharing, adaptation, distribution and reproduction in any medium or format, as long as you give appropriate credit to the original author(s) and the source, provide a link to the Creative Commons licence, and indicate if changes were made. The images or other third party material in this article are included in the article's Creative Commons licence, unless indicated otherwise in a credit line to the material. If material is not included in the article's Creative Commons licence and your intended use is not permitted by statutory regulation or exceeds the permitted use, you will need to obtain permission directly from the copyright holder. To view a copy of this licence, visit http://creativecommons.org/licenses/by/4.0/. The Creative Commons Public Domain Dedication waiver (http://creativeco mmons.org/publicdomain/zero/1.0/) applies to the data made available in this article, unless otherwise stated in a credit line to the data. 
producing organisms (29,59.2\%). Male sex $[p=0.031]$, an ASA score $\geq 2[p=0.020)$, administration of general anaesthesia $[p=0.018]$ and elevated fasting glucose $[p=0.033]$ were predictive of SSI.

Conclusion: The incidence of SSI in this study is comparable to other low- and middle-income countries, but a substantial proportion of these postoperative wounds have an ESBL-producing Enterobacteriaceae. Therefore, routine surveillance of SSI and related antibiotic resistance is required in resource-limited settings.

Keywords: Surgical site infections, Enterobacteriaceae, Sierra Leone, Antibiotic resistance, Extended spectrum betalactamase

\section{Introduction}

Surgical site infections (SSI) are a major public health threat to the success of global surgery, especially in developing countries. Although there is no comprehensive global data, the prevalence of SSI in low- and middleincome countries (LMICs) is higher than that in highincome countries (HICs) [1]. According to estimates by the World Health Organization (WHO) in 2011, the incidence of SSI in HICs ranges from 1.2 to $5.2 \%$, while that in LMICs is $10.8 \%$ [2]. Chu reports that the incidence of SSI in HICs is 9.4\%, while that in LMICs is $23.2 \%$ [3]. In sub-Saharan Africa, the prevalence of SSI is $16 \%$, ranging from 6.8 to $26 \%$ [4].

The high burden of SSI in LMICs clearly demonstrates the need to strengthen global support for low-income countries to improve surgical outcomes. Global initiatives to improve surgical outcomes have been developed for use, especially for LMICs. The WHO guidelines for the use of the WHO surgical safety checklist to prevent SSI are one of the global quality initiatives to improve surgical outcomes in under-resourced settings [5]. Although the use of the checklist has expanded globally, the results of a multi-country collaborative study show that it is ineffective in improving surgical outcomes if local preventive measures are not followed [6]. Hence, a more comprehensive approach is needed to prevent and control SSI.

The adverse effects of SSI on the health system and patients and their caregivers further prove the necessity of prevention, as they increase healthcare costs, lengthen hospital stays, and increase postoperative morbidity and mortality [7]. Complicating the problem is the intertwined relationship between SSI and the increasing burden of antimicrobial resistance, which is exacerbated by the inappropriate use of antibiotics in surgical prophylaxis and poor infection prevention and control practices [8]. Despite these huge challenges in preventing SSI and antibiotic resistance, there are limited data on SSI-related antibiotic resistance in many countries in sub-Saharan Africa.

In response to the 2014/2016 ebola epidemic in Sierra Leone, a National Infection Prevention and Control Policy that includes surveillance and control of SSIs and other HAIs was developed [9]. Yet, there is limited information in the literature on the incidence and risk factors of SSI and the related antibiotic resistance needed to guide their prevention and optimal management. Previous studies conducted at hospitals in Sierra Leone recorded an SSI prevalence rates between 7.3 and 10.9\% in caesarean section wounds $[10,11]$. However, the relevance of these studies is limited to describing the prevalence and risk factors of SSI at the level of maternal care. There are no data on postoperative wound isolates and their antibiotic resistance. It is worthwhile, therefore, to provide more comprehensive data on surgical site infections in Sierra Leone to inform public health policies and practices.

In this study, we aimed to establish the incidence and risk factors of SSIs and assess the related antibiotic resistance among adults attending an urban tertiary hospital, and a secondary health facility in Freetown to inform interventions on the prevention and control of SSIs in Sierra Leone and similar countries.

\section{Methods}

\section{Study design}

This is an observational prospective cohort study designed to collect data from patients participating in elective and emergency surgeries.

\section{Study setting}

The study was conducted at an urban tertiary hospital and secondary health facility in Freetown, Sierra Leone. The tertiary hospital was established to conduct research and provides training and clinical services. In total, the hospital has a capacity of 300 beds. Five of the 10 wards of the hospital admit surgical cases including those operated in the two surgical theatres. An average of 20 adult patients a week undergoes surgeries in this hospital, of which about 16 are elective cases. Unlike the tertiary hospital which provides surgical services to only nonpregnant patients, the secondary hospital provides both surgical and obstetric services. It has a total of 42 beds and performs an average of 4 surgeries a week. 


\section{Sample size}

We used a standard sample size calculation with an $\alpha$ of 0.05 , and a power of 0.8 to obtain a minimum sample size of 224 surgical case. In total, however, 245 and 93 post-operative patients were recruited at the tertiary and secondary hospitals, respectively.

\section{Sampling, clinical procedure and definitions}

Adult (18 years or older) patients who had both elective and emergency surgeries at the selected tertiary and secondary hospitals were sequentially enrolled in the study from February 09, 2021 to July 31, 2021 (estimated at 22 weeks). The eligibility criteria for inclusion in the study were patients who participated in either emergency or elective surgeries and were 18 years or older. Patients who refused consent, had amputations or other bone surgeries and patients whose infected wounds were not classified as SSI by definition (patients with suture abscesses, local puncture wounds, traumarelated wounds, episiotomy or infected burn wounds) were excluded from the study.

Two trained nurses (one in each hospital) collected the data on the assessment of surgical site infections, and their risk factors from the patients' files as recorded by the managing teams, and by patients/ward nurses' interviews.

Patients were first recruited in the preoperative/perioperative ward of the hospital to obtain consent and detailed information on their socio-demographic characteristics and preoperative preparation. After the surgery, patients were followed-up at the post-operative wards to obtain documented intraoperative information on their records. During routine wound cleaning, weekly follow-up evaluations were performed in the minor operating room of the hospitals to evaluate the wound status and physiological parameters. Follow-up evaluation continued until the wound had healed or 30 days after surgery, which is usually the prescribed period for the development of SSI without implants [12]. Patients who may have decided to obtain postoperative services at other institutions or request that their care be transferred to other institutions to continue their postoperative care were followed up directly by phone or through their service providers.

Clinically, a wound was identified as an SSI if it occurred within 30 days post-surgery and had at least a purulent discharge from the incision, local swelling, redness, pain or tenderness, wound abscess, foul smell, or fever [13]. Wound swabs were collected from the patients with an SSI and sent to the laboratory for bacterial culture and Antibiotic Susceptibility Testing (AST).

\section{Laboratory procedure}

Upon reaching the laboratory, wound swab samples were streaked onto the chromogenic agar plate (CHROMagar $^{\mathrm{TM}}$ orientation) and incubated aerobically at $37{ }^{\circ} \mathrm{C}$ for 18 to $24 \mathrm{~h}$. Where there was a bacterial growth, a colony was picked and streaked onto a Brain Heart Infusion (BHI) agar plate for purification and Gram staining. All isolates were cultured twice to ensure they were pure but there were no discordant results.

A VITEK 2 compact system (bioMérieux, France) was used for identification and antibiotic susceptibility testing of isolates from pure cultures. Using a DensiCHEK Plus turbidimeter (bioMérieux, France), a solution of bacteria in saline was prepared in polystyrene tubes (bioMérieux, France) to levels between 0.5 and 0.63 MacFarland standard. Antibiotic susceptibility tests were performed by adding $145 \mu \mathrm{l}$ (for gram-negative bacteria) or $280 \mu \mathrm{l}$ (for gram-positive bacteria) of suspension into a new polystyrene tube as per the manufacturer's instructions.

The isolates suspensions were loaded on the VITEK 2 compact system and incubated overnight at $37{ }^{\circ} \mathrm{C}$. All the culture and antibiotic susceptibility results generated were printed and dispatched to the research team.

\section{Definition of termsof terms [12, 13] \\ Wound classification based on the potential of infection}

- Clean wound is an uninfected operative wound in which no inflammation is encountered and the respiratory, alimentary, genital or uninfected urinary tracts are not entered

- Clean-contaminated wound is an operative wound in which the respiratory, alimentary, genital or urinary tracts are entered under controlled conditions and without unusual contamination.

- Contaminated wound is an open, fresh, accidental wound.

- Dirty wound is an old traumatic wound with retained devitalized tissue or wound involving existing clinical infection or perforated viscera.

\section{Wound classification based on the extent of involvement}

- Superficial surgical site infection confines to the skin and subcutaneous tissue and it is characterised by the presence of either purulent drainage with or without laboratory confirmation or microbial isolates from superficial incision or the presence of signs and symptoms of infection at the site, or diagnosis of SSI by clinician. 
- Deep surgical site infections is the presence of at least purulent drainage from the deep incision, spontaneous dehisces or a deliberately opened deep incision in a patient with at least one of the following signs or symptoms: fever $\left(>38{ }^{\circ} \mathrm{C}\right)$, localized pain, or tenderness, unless site is culture-negative, an abscess or other evidence of infection involving the deep incision soft tissues or diagnosis of a deep incisional SSI by the attending clinician.

- Organ/space SSI is an infection which involves any part of the anatomy other than the incision, which was opened or manipulated during an operation and at least purulent drainage from a drain that is placed through a stab wound into the organ/space, isolate from an aseptically obtained culture of fluid or tissue in the organ/space, abscess or other evidence of infection involving the organ/space that is found on direct examination, during re-operation, or by histopathologic or radiologic examination, and diagnosis of an organ/space SSI by a surgeon or attending physician.

\section{Data collection}

The data was collected using a password-protected Epidata platform. On the preoperative/perioperative wards, socio-demographic variables and data on the underlying surgical condition, duration of hospitalization before surgery, body mass index, comorbidities, and preoperative skin preparations were entered into the Epidata software. The employment status of the study participants were categorized into unemployed, retired, student, informal sector (artisans, traders, farmers, fishing etc.) and formal sector (civil servants, teachers, police, military etc.).

The American Society of Anesthesiologists' (ASA) preoperative assessment score was evaluated for each patient according to preoperative physical status [14].

Information on intraoperative surgical interventions was collected on the post-operative wards. Further assessment of the risk factors for surgical site infections involved the collection of data on antibiotic use postsurgery, the duration of postoperative admission, use of central and peripheral vascular lines, urinary catheters, nasogastric tubes, and duration of surgical drains.

The bacterial culture data were recorded at the end of the admission.

\section{Data management and analysis}

Data were exported from Epi-Data platform into Microsoft Excel, cleaned, coded and transferred into STATA version 16 (StataCorp LLC) for analysis. Descriptive statistics such as frequencies and percentages were used to present demographic and clinical characteristics of the study participants. Univariate and multivariable logistic regression were used to identify factors associated with surgical site infections (SSIs). Variables which had a $p$ value $<0.25$ in the univariate logistic regression model were fitted to the multivariable logistic regression model to identify predictors of SSIs. Findings were presented as crude odds ratio after univariate analysis, and adjusted odds ratio (aOR) following multivariable analysis, with their $95 \%$ confidence intervals (CI). A $p$ value of less than 0.05 was considered statistically significant.

\section{Ethical consideration}

Ethical approval was obtained from the Sierra Leone Ethics and Scientific Review Committee of the Ministry of Health and Sanitation. Prior to the start of the study, permission was obtained from the administrations of the hospitals and heads of departments.

A participant information sheet was provided to all patients prior to their recruitment or was read aloud for those unable to read. Informed written consent was taken with signatures or thumbprints (for participants unable to read).

Participants who refused to consent were still offered appropriate management or advice but their details were not recorded for the purposes of the study. Participants were free to withdraw at any time, without giving a reason up until the completion of the study. Swab cultures and blood glucose checks requested for the purpose of the research were at no cost to participants.

\section{Results}

\section{Demographic characteristics of study participants}

A total of 338 patients were followed up for 30 days after surgery. Of this, 245 (72.5\%) and 93 (27.5\%) had surgery at the tertiary and secondary hospitals, respectively.

The majority were males 192 (56.8\%), less than 35 years 164 (48.5\%), and married 208 (61.5\%). The highest educational attainment of the patients was secondary level 155 (46\%). Many patients worked in the informal sector 175 (51.8\%), never took alcohol 295 (87.3\%), or smoked cigarettes 293 (86.7\%). Other details of the patients' sociodemographic characteristics are presented in Table 1.

\section{Details of the clinical characteristics and surgical management of the study participants}

Most 313 (92.6\%) patients had a body mass index (BMI) below $25 \mathrm{~kg} / \mathrm{m}^{2}$, and $89(26.3 \%)$ patients had comorbidities. Preoperatively, 134 (39.8\%) patients were admitted to the hospital for more than $24 \mathrm{~h}$ and received antibiotic therapy $90(26.6 \%)$ and blood transfusion 25 (7.4\%). Only $64(18.9 \%)$ patients had an ASA score of 2 and above. Most 213 (63\%) surgeries were abdominal. Forty 
Table 1 Socio-demographic characteristics of the study participants $(\mathrm{N}=338)$

\begin{tabular}{|c|c|c|}
\hline Variables & Frequency & $\%$ \\
\hline \multicolumn{3}{|l|}{ Hospital } \\
\hline Secondary hospital & 93 & 27.5 \\
\hline Tertiary hospital & 245 & 72.5 \\
\hline \multicolumn{3}{|l|}{ Sex } \\
\hline Female & 146 & 43.2 \\
\hline Male & 192 & 56.8 \\
\hline \multicolumn{3}{|l|}{ Age } \\
\hline$<35$ & 164 & 48.5 \\
\hline $35-60$ & 147 & 43.5 \\
\hline$>60$ & 27 & 8.0 \\
\hline \multicolumn{3}{|l|}{ Marital status } \\
\hline Single & 107 & 31.7 \\
\hline Married & 208 & 61.5 \\
\hline Divorced/separated/widowed & 23 & 6.8 \\
\hline \multicolumn{3}{|l|}{ Level of education } \\
\hline None & 87 & 25.8 \\
\hline Primary & 26 & 7.7 \\
\hline Secondary & 155 & 46.0 \\
\hline Tertiary & 69 & 20.5 \\
\hline \multicolumn{3}{|l|}{ Occupation } \\
\hline Unemployed & 16 & 4.7 \\
\hline Student & 51 & 15.1 \\
\hline Informal sector & 175 & 51.8 \\
\hline Formal sector & 87 & 25.7 \\
\hline Retired & 9 & 2.7 \\
\hline \multicolumn{3}{|l|}{ Alcohol consumption } \\
\hline No & 295 & 87.3 \\
\hline Yes & 43 & 12.7 \\
\hline \multicolumn{3}{|l|}{ Cigarette smoking } \\
\hline No & 293 & 86.7 \\
\hline Yes & 45 & 13.3 \\
\hline \multicolumn{3}{|l|}{ Other substance use } \\
\hline No & 332 & 98.2 \\
\hline Yes & 6 & 1.8 \\
\hline
\end{tabular}

patients (11.8\%) had elevated fasting blood glucose levels of $5.6 \mathrm{mmol} / \mathrm{l}$ or higher (Table 2).

All the patients underwent some form of skin preparation before surgery. Among them, 295 (87.3\%) had nonantiseptic pre-operative shower, $2(0.6 \%)$ had antiseptic pre-operative shower, and 314 (92.9\%) had hair removal by shaving.

In 157 (46.5\%) cases, patients received either local or spinal anesthesia, and in $45(13.3 \%)$ cases, the operation lasted at least $2 \mathrm{~h}$. The number of surgeries attended by more than 2 surgeons was 73 (21.6\%), whereas 13 (3.9\%) and 119 (35.2\%) surgeries, respectively were attended by
Table 2 Clinical characteristics of study participants $(\mathrm{N}=338)$

\begin{tabular}{|c|c|c|}
\hline Variables & Frequency & $\%$ \\
\hline \multicolumn{3}{|l|}{ ASA score } \\
\hline$<2$ & 274 & 81.1 \\
\hline$\geq 2$ & 64 & 18.9 \\
\hline \multicolumn{3}{|l|}{ Surgical site } \\
\hline Non abdominal & 63 & 18.6 \\
\hline Intra-abdominal & 213 & 63.0 \\
\hline Obstetric & 62 & 18.3 \\
\hline \multicolumn{3}{|l|}{ BMI } \\
\hline$<25$ & 313 & 92.6 \\
\hline$\geq 25$ & 25 & 7.4 \\
\hline \multicolumn{3}{|l|}{ Pre-op blood transfusion } \\
\hline No & 312 & 92.6 \\
\hline Yes & 25 & 7.4 \\
\hline \multicolumn{3}{|l|}{ Comorbidities } \\
\hline Absent & 249 & 73.7 \\
\hline Present & 89 & 26.3 \\
\hline \multicolumn{3}{|l|}{ Pre-op admission } \\
\hline$\leq 24 \mathrm{~h}$ & 203 & 60.2 \\
\hline$>24 \mathrm{~h}$ & 134 & 39.8 \\
\hline \multicolumn{3}{|l|}{ Pre-op antibiotics } \\
\hline No & 248 & 73.4 \\
\hline Yes & 90 & 26.6 \\
\hline \multicolumn{3}{|l|}{ Surgery duration } \\
\hline$<120 \min$ & 293 & 86.7 \\
\hline$\geq 120 \mathrm{~min}$ & 45 & 13.3 \\
\hline \multicolumn{3}{|l|}{ Type of anaesthesia } \\
\hline Local/spinal & 157 & 46.5 \\
\hline General & 181 & 53.5 \\
\hline \multicolumn{3}{|l|}{ Type of suture } \\
\hline Absorbable only & 137 & 40.5 \\
\hline Non-absorbable only & 83 & 24.6 \\
\hline Both & 12 & 3.6 \\
\hline Not reported & 106 & 31.4 \\
\hline \multicolumn{3}{|l|}{ Intra-op blood transfusion } \\
\hline No & 293 & 86.9 \\
\hline Yes & 44 & 13.1 \\
\hline \multicolumn{3}{|l|}{ Number of surgeons } \\
\hline$\leq 2$ & 265 & 78.4 \\
\hline$>2$ & 73 & 21.6 \\
\hline \multicolumn{3}{|l|}{ Number of scrub nurses } \\
\hline 1 & 325 & 96.1 \\
\hline$>1$ & 13 & 3.9 \\
\hline \multicolumn{3}{|l|}{ Number of anaesthetists } \\
\hline 1 & 219 & 64.8 \\
\hline$>1$ & 119 & 35.2 \\
\hline \multicolumn{3}{|l|}{ Intra-op antibiotics } \\
\hline No & 104 & 30.9 \\
\hline Yes & 233 & 69.1 \\
\hline Type of wound & & \\
\hline
\end{tabular}


Table 2 (continued)

\begin{tabular}{|c|c|c|}
\hline Variables & Frequency & $\%$ \\
\hline Clean & 191 & 56.5 \\
\hline Clean-contaminated & 116 & 34.3 \\
\hline Contaminated & 31 & 9.2 \\
\hline \multicolumn{3}{|l|}{ Post op antibiotics } \\
\hline No & 55 & 16.3 \\
\hline Yes & 282 & 83.7 \\
\hline \multicolumn{3}{|l|}{ Post op NG tube } \\
\hline No & 296 & 88.1 \\
\hline Yes & 40 & 11.9 \\
\hline \multicolumn{3}{|l|}{ Post op urinary catheter } \\
\hline No & 199 & 58.9 \\
\hline Yes & 139 & 41.1 \\
\hline \multicolumn{3}{|l|}{ Surgical drains use } \\
\hline No & 266 & 78.9 \\
\hline Yes & 71 & 21.1 \\
\hline \multicolumn{3}{|c|}{ Impaired glucose tolerance } \\
\hline No & 298 & 88.2 \\
\hline Yes & 40 & 11.8 \\
\hline \multicolumn{3}{|l|}{ Surgical site infection (SSI) } \\
\hline Absent & 299 & 88.5 \\
\hline Present & 39 & 11.5 \\
\hline \multicolumn{3}{|l|}{ Type of SSI } \\
\hline Superficial & 27 & 69.0 \\
\hline Deep & 12 & 31.0 \\
\hline
\end{tabular}

more than one scrub nurse or anesthetist. Most surgical wounds were clean 191 (56.5\%). During surgery, antibiotics were administered to $233(69.1 \%)$ patients, and the number of patients with a blood transfusion increased to $44(13.1 \%)$. Although the type of suture material used was not reported in 106 (31.4\%) cases, in 137 (40.5\%) cases, absorbable sutures were used for wound closure.

Postoperatively, 71 (21.1\%) patients had at least one surgical drainage tube placed; 40 (11.9\%) and 139 (41.1\%) patients had nasogastric and urinary catheters placed in situ, respectively. Antibiotics were given to 282 (83.7\%) patients. See Table 2 for details.

\section{Incidence and characteristics of surgical site infections} Overall, 39 (11.5\%) patients developed a surgical site infection (SSI). Of the 39 cases of SSI, 27 (69\%) were deep, while 12 (31\%) were superficial. Of the 39 patients who developed SSI, 7 (17.9\%) were from secondary hospital, while $32(82.1 \%)$ had their treatment in the tertiary hospital. The incidence of SSI is higher in contaminated $17(43.6 \%)$ than in clean-contaminated 12 (30.8\%) and clean 10 (25.6\%) wounds (Tables 2 and 3 ).
Factors associated with surgical site infection

Following univariate logistic regression, ASA score of $\geq 2(p<0.001)$, pre-op admission of more than $24 \mathrm{~h}$ $(p=0.001)$, administration of antibiotics pre-operatively $(p<0.001)$, duration of surgery $\geq 2 \mathrm{~h}(p=0.019)$, administration of general anaesthesia $(p<0.001)$, intraoperative blood transfusion $(p<0.001)$, having more than 2 surgeons participating in a surgery $(p=0.008)$, contaminated wound $(p<0.001)$, elevated fasting glucose levels $\geq 5.6 \mathrm{mmol} / \mathrm{l}(p=0.025)$, and placement of postoperative nasogastric tube $(p<0.001)$, urinary catheter $(p<0.001)$ and surgical drain $(p<0.001)$ were statistically associated with development of a surgical site infection. Other factors with $p<0.25$ were sex, site of surgery, preoperative blood transfusion, hospital study site, number of anaesthetists at surgery, intraoperative antibiotics as well as use of antibiotics postoperatively (Table 3).

Multivariable logistic regression showed that male patients [aOR 3.9, 95\% CI (1.13-13.33); $p=0.031$ ] and patients with an ASA score of $\geq 2$ [aOR 4.1, 95\% CI $(1.26-13.50) ; p=0.020)$ were four times more likely to develop SSI. Contaminated surgical wounds were over six times more likely to become infected compared to clean wounds, [aOR 6.5, 95\% CI (1.04-40.20); $p=0.045$ ]. Being on admission for more than $24 \mathrm{~h}$ prior to surgery [aOR 4.1, 95\% CI (1.47-11.66); $p=0.007$ ], elevated fasting glucose was a statistically significant predictor of surgical site infection, [aOR 3.5, 95\% CI (1.10-10.91); $p=0.033$ ] and use of general anaesthesia [aOR 6.8, 95\% CI (1.40-33.08); $p=0.018$ ], were predictive of SSI. When more than two surgeons attended the surgery, patients were $70 \%$ less likely to have infected wounds, [aOR 0.30 , 95\% CI (0.09-0.97); $p=0.045]$. See Table 4 for details (Table 3).

\section{Profile of bacterial isolates and antibiotics resistance patterns}

Of patients who developed an SSI, wound swabs were collected in $29(74.4 \%)$ patients and $18(62.1 \%)$ had bacterial growth. In total, 49 isolates of 14 different bacteria including both gram negative $(41,83.7 \%)$ and gram positive $(8,16.3 \%)$ isolates were identified. Of these, 32 (65.3\%) are Enterobacteriaceae, 9 (18.4\%) were Non-fermenting gram-negative bacilli, and 8 (16.3\%) are grampositive cocci. The most common isolates are Escherichia coli 12 (24.5\%), Klebsiella pneumoniae spp pneumonia 10 (20.4\%), Acinetobacter baumannii complex 5 (10.2\%), Klebsiella oxytoca $(4,8.2 \%)$ and Enterococcus faecalis (4, 8.2\%). The Enterobacteriaceae were either resistance to carbapenems $4(8.2 \%)$ or were extended-spectrum betalactamase (ESBL) producing organisms 29 (59.2\%). There 
Table 3 Univariate and multivariable logistic regression of factors associated with surgical site infection

\begin{tabular}{|c|c|c|c|c|c|c|}
\hline \multirow[t]{2}{*}{ Variables } & \multicolumn{2}{|c|}{ Surgical site infection } & \multirow{2}{*}{$\begin{array}{l}\text { Crude odds ratio } \\
\text { (confidence interval) }\end{array}$} & \multirow[t]{2}{*}{$p$ value } & \multirow{2}{*}{$\begin{array}{l}\text { Adjusted odds ratio } \\
\text { (confidence interval) }\end{array}$} & \multirow[t]{2}{*}{$p$ value } \\
\hline & $\begin{array}{l}\text { Yes N (\%) } \\
39(11.5)\end{array}$ & $\begin{array}{l}\text { No N (\%) } \\
299(88.5)\end{array}$ & & & & \\
\hline \multicolumn{7}{|l|}{ Hospital study site } \\
\hline Secondary & $7(17.9)$ & $86(28.8)$ & 1 & & 1 & \\
\hline Tertiary & $32(82.1)$ & $213(71.2)$ & $1.85(0.78-4.34)$ & 0.160 & $4.8(0.62-36.91)$ & 0.132 \\
\hline \multicolumn{7}{|l|}{ Sex } \\
\hline Female & $13(33.3)$ & $133(44.5)$ & 1 & & 1 & \\
\hline Male & $26(66.7)$ & $166(55.5)$ & $1.6(0.79-3.24)$ & 0.189 & $3.9(1.13-13.33)$ & 0.031 \\
\hline \multicolumn{7}{|l|}{ Age } \\
\hline$<35$ & $19(48.7)$ & $145(48.5)$ & 1 & & & \\
\hline $35-60$ & $16(41.0)$ & $131(43.8)$ & $0.93(0.46-1.89)$ & 0.845 & & \\
\hline$>60$ & $4(10.3)$ & $23(7.7)$ & $1.33(0.41-4.25)$ & 0.634 & & \\
\hline \multicolumn{7}{|l|}{ Marital status } \\
\hline Single & $12(30.8)$ & $95(31.8)$ & 1 & & & \\
\hline Married & $26(66.7)$ & $182(60.9)$ & $1.13(0.55-2.34)$ & 0.740 & & \\
\hline Divorced/separated/widowed & $1(2.5)$ & $22(7.3)$ & $0.36(0.04-2.91)$ & 0.338 & & \\
\hline \multicolumn{7}{|l|}{ Alcohol consumption } \\
\hline No & $33(84.6)$ & $262(87.6)$ & 1 & & & \\
\hline Yes & $6(15.4)$ & $37(12.4)$ & $1.29(0.51-3.28)$ & 0.597 & & \\
\hline \multicolumn{7}{|l|}{ Cigarette smoking } \\
\hline No & $33(84.6)$ & $260(87.0)$ & 1 & & & \\
\hline Yes & $6(15.4)$ & $39(13.0)$ & $1.21(0.48-3.08)$ & 0.689 & & \\
\hline \multicolumn{7}{|l|}{ ASA } \\
\hline$<2$ & $15(38.5)$ & $259(86.6)$ & 1 & & 1 & \\
\hline$\geq 2$ & $24(61.5)$ & $40(13.4)$ & $10.4(5.01-21.41)$ & $<0.001$ & $4.1(1.26-13.50)$ & 0.020 \\
\hline \multicolumn{7}{|l|}{$\mathrm{BMI}$} \\
\hline$<25$ & $37(94.9)$ & $276(92.3)$ & 1 & & & \\
\hline$\geq 25$ & $2(5.1)$ & $23(7.7)$ & $0.65(0.15-2.86)$ & 0.568 & & \\
\hline \multicolumn{7}{|l|}{ Site of surgery } \\
\hline Non abdominal & $4(10.3)$ & $59(19.7)$ & 1 & & 1 & \\
\hline Intra-abdominal & $31(79.5)$ & $182(60.9)$ & $2.51(0.85-7.41)$ & 0.095 & $1.4(0.33-5.90)$ & 0.659 \\
\hline Caesarian sections & $4(10.3)$ & $58(19.4)$ & $1.02(0.24-4.26)$ & 0.981 & $2.0(0.14-30.05)$ & 0.608 \\
\hline \multicolumn{7}{|l|}{ Pre-op blood transfusion } \\
\hline No & $33(84.6)$ & $279(93.6)$ & 1 & & 1 & \\
\hline Yes & $6(15.4)$ & $19(6.4)$ & $2.67(0.99-7.16)$ & 0.051 & $0.3(0.06-1.30)$ & 0.105 \\
\hline \multicolumn{7}{|l|}{ Comorbidities } \\
\hline Absent & $27(69.2)$ & $222(74.3)$ & 1 & & & \\
\hline Present & $12(30.8)$ & $77(25.7)$ & $1.28(0.62-2.65)$ & 0.504 & & \\
\hline \multicolumn{7}{|l|}{ Pre-op admission } \\
\hline$\leq 24 \mathrm{~h}$ & $14(35.9)$ & $189(63.4)$ & 1 & & 1 & \\
\hline$>24 \mathrm{~h}$ & $25(64.1)$ & $109(36.6)$ & $3.1(1.54-6.21)$ & 0.001 & $4.1(1.47-11.66)$ & 0.007 \\
\hline \multicolumn{7}{|l|}{ Pre-op antibiotics } \\
\hline No & $16(41)$ & $232(77.6)$ & 1 & & 1 & \\
\hline Yes & $23(59)$ & $67(22.4)$ & $5.0(2.49-9.96)$ & $<0.001$ & $1.2(0.43-3.52)$ & 0.700 \\
\hline \multicolumn{7}{|l|}{ Surgery duration } \\
\hline$<120 \min$ & $29(74.4)$ & $264(88.3)$ & 1 & & 1 & \\
\hline$\geq 120 \mathrm{~min}$ & $10(25.6)$ & $35(11.7)$ & $2.6(1.17-5.79)$ & 0.019 & $1.2(0.38-3.85)$ & 0.738 \\
\hline \multicolumn{7}{|l|}{ Type of anaesthesia } \\
\hline Local/spinal & $6(15.4)$ & $151(50.5)$ & 1 & & 1 & \\
\hline
\end{tabular}


Table 3 (continued)

\begin{tabular}{|c|c|c|c|c|c|c|}
\hline \multirow[t]{2}{*}{ Variables } & \multicolumn{2}{|c|}{ Surgical site infection } & \multirow{2}{*}{$\begin{array}{l}\text { Crude odds ratio } \\
\text { (confidence interval) }\end{array}$} & \multirow[t]{2}{*}{$p$ value } & \multirow{2}{*}{$\begin{array}{l}\text { Adjusted odds ratio } \\
\text { (confidence interval) }\end{array}$} & \multirow[t]{2}{*}{$p$ value } \\
\hline & $\begin{array}{l}\text { Yes N (\%) } \\
39(11.5)\end{array}$ & $\begin{array}{l}\text { No N (\%) } \\
299(88.5)\end{array}$ & & & & \\
\hline General & $33(84.6)$ & $148(49.5)$ & $5.6(2.28-13.79)$ & $<0.001$ & $6.8(1.40-33.08)$ & 0.018 \\
\hline \multicolumn{7}{|l|}{ Intra-op blood transfusion } \\
\hline No & $23(59)$ & $270(90.6)$ & 1 & & 1 & \\
\hline Yes & $16(41)$ & $28(9.4)$ & $6.7(3.18-14.16)$ & $<0.001$ & $2.1(0.58-7.55)$ & 0.263 \\
\hline \multicolumn{7}{|l|}{ Number of surgeons } \\
\hline$\leq 2$ & $24(61.5)$ & $241(80.6)$ & 1 & & 1 & \\
\hline$>2$ & $15(38.5)$ & $58(19.4)$ & $2.6(1.28-5.26)$ & 0.008 & $0.3(0.09-0.97)$ & 0.045 \\
\hline \multicolumn{7}{|l|}{ Number of scrub nurses } \\
\hline 1 & $37(94.9)$ & $288(96.3)$ & 1 & & & \\
\hline$>1$ & $2(5.1)$ & $11(3.7)$ & $1.4(0.30-6.63)$ & 0.660 & & \\
\hline \multicolumn{7}{|l|}{ Number of anaesthetists } \\
\hline 1 & $22(56.4)$ & $197(65.9)$ & 1 & & 1 & \\
\hline$>1$ & $17(43.6)$ & $102(34.1)$ & $1.5(0.76-2.93)$ & 0.246 & $1.3(0.51-3.41)$ & 0.565 \\
\hline \multicolumn{7}{|l|}{ Intra-op antibiotics } \\
\hline No & $7(17.9)$ & $97(32.5)$ & 1 & & 1 & \\
\hline Yes & $32(82.1)$ & $201(67.5)$ & $2.2(0.94-5.18)$ & 0.069 & $0.8(0.22-3.24)$ & 0.806 \\
\hline \multicolumn{7}{|l|}{ Type of wound } \\
\hline Clean & $10(25.6)$ & $181(60.5)$ & 1 & & 1 & \\
\hline Clean-contaminated & $12(30.8)$ & $104(34.8)$ & $2.1(0.87-5.00)$ & 0.098 & $0.8(0.19-3.52)$ & \\
\hline Contaminated & $17(43.6)$ & $14(4.7)$ & $22.0(8.49-56.93)$ & $<0.001$ & $6.5(1.04-40.20)$ & 0.045 \\
\hline \multicolumn{7}{|l|}{ Post-op antibiotics } \\
\hline No & $3(7.7)$ & $52(17.5)$ & 1 & & 1 & \\
\hline Yes & $36(92.3)$ & $246(82.5)$ & $2.5(0.75-8.55)$ & 0.133 & $0.4(0.09-2.07)$ & 0.289 \\
\hline \multicolumn{7}{|l|}{ Post-op NG tube } \\
\hline No & $24(63.2)$ & $272(91.3)$ & 1 & & 1 & \\
\hline Yes & $14(36.8)$ & $26(8.7)$ & $6.1(2.82-13.21)$ & $<0.001$ & $0.7(0.19-2.62)$ & 0.610 \\
\hline \multicolumn{7}{|l|}{ Urinary catheter } \\
\hline No & $11(28.2)$ & $188(62.9)$ & 1 & & 1 & \\
\hline Yes & $28(71.8)$ & $111(37.1)$ & $4.3(2.07-9.00)$ & $<0.001$ & $3.9(0.98-15.20)$ & 0.053 \\
\hline \multicolumn{7}{|l|}{ Surgical drains use } \\
\hline No & $16(41)$ & $250(83.9)$ & 1 & & & \\
\hline Yes & $23(59)$ & $48(16.1)$ & $7.5(3.69-15.21)$ & $<0.001$ & $0.5(0.10-3.00)$ & 0.485 \\
\hline \multicolumn{7}{|c|}{ Impaired glucose tolerance } \\
\hline No & $30(76.9)$ & $268(89.6)$ & 1 & & 1 & \\
\hline Yes & $9(23.1)$ & $31(10.4)$ & $2.6(1.13-5.96)$ & 0.025 & $3.5(1.10-10.91)$ & 0.033 \\
\hline
\end{tabular}

Bold values indicate the statistically significant

were no carbapenem-resistant non-fermenting gram negative bacilli (Table 4).

Most of the gram negative bacteria isolates are resistant to quinolones, penicillins, some aminoglycosides and second, third and fourth generation cephalosporin. Susceptibility to piperacillin/tazobactam, amikacin and carbapenems was recorded for many gram negative pathogens (Table 5). Again, all the Enterococci and $S$. haemolyticus have good susceptibility to tegecycline, vancomycin and linezolid (Table 6).

\section{Discussion}

For the first time, we have provided more comprehensive data on surgical site infections at different levels of surgical care in Sierra Leone.

The incidence rate of surgical site infections in the two hospitals is $11.5 \%$ which is similar to the previously reported SSI incidence rates of $7.3 \%$ and $10.9 \%$ in Sierra Leone $[10,11]$. Although the incidence of SSI reported in this study is similar to the WHO's global estimates of $10.8 \%$ in low- and middle-income countries [1], the 
Table 4 Bacterial isolates and patterns of antibiotic resistance of isolates from post-operative wounds

\begin{tabular}{|c|c|c|c|c|c|}
\hline Bacterial isolates & $\mathrm{N}=49$ & $\%$ & Resistant patterns of isolates & $\mathbf{N}$ & $\%$ \\
\hline Enterobacteriacea & 32 & 65.3 & Enterobacteriacea & 32 & 65.3 \\
\hline Escherichia coli & 12 & 24.5 & $\begin{array}{l}\text { Extended-spectrum beta-lactamase (ESBL) pro- } \\
\text { ducing organisms }\end{array}$ & 29 & 59.2 \\
\hline Klebsiella pneumoniae ssp pneumonia & 10 & 20.4 & Carbapenem resistance Enterobacteriacea & 4 & 8.2 \\
\hline Klebsiella oxytoca & 4 & 8.2 & & & \\
\hline Proteus mirabilis & 3 & 6.2 & & & \\
\hline Morganella morganii ssp morganii & 1 & 2.0 & & & \\
\hline Providencia stuartii & 1 & 2.0 & & & \\
\hline Serratia fonticola & 1 & 2.0 & & & \\
\hline Non-fermenters & 9 & 18.4 & Non-fermenters & & \\
\hline Acinetobacter baumannii complex & 5 & 10.2 & Carbapenem-resistant A. baumanii (CRAB) & 0 & 0.0 \\
\hline Pseudomonas aeruginosa & 3 & 6.2 & Carbapenem-resistant $P$. aeruginosa (CRPA) & 0 & 0.0 \\
\hline Pseudomonas luteola & 1 & 2.0 & & 0 & 0.0 \\
\hline Gram positive cocci & 8 & 16.3 & Vancomycin resistance Enterococci & & \\
\hline Enterococcus faecalis & 5 & 10.2 & & & \\
\hline Enterococcus raffinosus & 1 & 2.0 & & & \\
\hline Staphylococcus haemolyticus & 1 & 2.0 & & & \\
\hline Kocuria kristinae & 1 & 2.0 & & & \\
\hline
\end{tabular}

Table 5 Antibiotic resistance profile of Gram-negative bacteria isolates

\begin{tabular}{|c|c|c|c|c|c|c|c|}
\hline \multirow[t]{2}{*}{ Antibiotics } & \multicolumn{7}{|c|}{ Resistance rate $(\%)^{\circledR}$} \\
\hline & $\begin{array}{l}\text { E. coli } \\
\mathrm{N}=12\end{array}$ & $\begin{array}{l}\text { K. pneumoniae } \\
N=10\end{array}$ & $\begin{array}{l}\text { Pseudomonas } \\
\text { spp. } \\
\mathrm{N}=4\end{array}$ & $\begin{array}{l}\text { A. baumanii } \\
\mathrm{N}=5\end{array}$ & $\begin{array}{l}\text { K. oxytoca } \\
\mathrm{N}=4\end{array}$ & $\begin{array}{l}\text { P. mirabilis } \\
\mathrm{N}=3\end{array}$ & $\begin{array}{l}\text { M. morgagni } \\
\mathrm{N}=1\end{array}$ \\
\hline Imipenem & 0.0 & 0.0 & 0.0 & 0.0 & 25.0 & 0.0 & 100.0 \\
\hline Meropenem & 0.0 & 0.0 & 0.0 & - & 25.0 & 0.0 & 0.0 \\
\hline Ampicillin & 81.8 & 100.0 & - & 80.0 & - & - & - \\
\hline Ampicillin-sulbactam & 75.0 & 81.8 & - & 20.0 & - & - & - \\
\hline Ciprofloxacin & 100.0 & 81.8 & 75.0 & 36.0 & 50.0 & 100.0 & 0.0 \\
\hline Levofloxacin & 100.0 & 54.5 & 75.0 & 40.0 & 50.0 & 0.0 & 0.0 \\
\hline Amikacin & 0.0 & 9.1 & 50.0 & 17.0 & 25.0 & 100.0 & 0.0 \\
\hline Gentamycin & 68.0 & 63.0 & 75.0 & 56.0 & 25.0 & 100.0 & 0.0 \\
\hline Tobramycin & 50.0 & 72.0 & 75.0 & 29.0 & 75.0 & 100.0 & 0.0 \\
\hline Aztreonam & 75.0 & 63.0 & - & - & 50.0 & - & - \\
\hline Co-trimoxazole & 83.3 & 72.0 & - & 93.0 & 75.0 & - & 0.0 \\
\hline Nitrofurantoin & 36.4 & 13.3 & - & 84.0 & 0.0 & - & 0.0 \\
\hline Ceftriaxone & 100.0 & 90.9 & - & 36.0 & 75.0 & - & 0.0 \\
\hline Cefuroxime & 100.0 & 100.0 & - & 100.0 & 100.0 & - & 100.0 \\
\hline Cefuroxime Axetil & 100.0 & 100.0 & - & 89.0 & 75.0 & - & 100.0 \\
\hline Cefotetan & 25.0 & 0.0 & - & 69.0 & 100.0 & - & 0.0 \\
\hline Cefazolin & 81.8 & 81.8 & - & 92.0 & 100.0 & - & 100.0 \\
\hline Ceftazidime & 100.0 & 100.0 & 0.0 & 46.0 & 100.0 & 0.0 & 0.0 \\
\hline Cefepime & 81.8 & 100.0 & 25.0 & 29.0 & 75.0 & 0.0 & 0.0 \\
\hline Piperacillin/tazobactam & 16.7 & 9.1 & 0.0 & 0.0 & 25.0 & 0.0 & 0.0 \\
\hline
\end{tabular}

${ }^{8}$ Percentages $=$ number of resistant antibiotics/total number of antibiotics tested

(-) indicate not tested 
Table 6 Antibiotic resistance pattern of Gram-positive bacteria

\begin{tabular}{|c|c|c|c|}
\hline & \multicolumn{3}{|c|}{ Resistance rate $(\%)^{\circledR}$} \\
\hline & E. faecalis $(\mathrm{N}=4)$ & $\begin{array}{l}E . \\
\text { raffinosus } \\
(\mathrm{N}=1)\end{array}$ & $\begin{array}{l}\text { S. } \\
\text { haemolyticus } \\
(\mathrm{N}=1)\end{array}$ \\
\hline Benzylpenicillin & 44.0 & 100.0 & 100.0 \\
\hline Oxacillin & - & - & 100.0 \\
\hline Ampicillin & 60.0 & 100.0 & 0.0 \\
\hline Ampicillin-sulbactam & 28.0 & 100.0 & 0.0 \\
\hline Erythromycin & 50.0 & - & 100.0 \\
\hline Clindamycin & 100.0 & 100.0 & 0.0 \\
\hline Quinupristin-dalfopristin & 100.0 & 0.0 & 0.0 \\
\hline Gentamycin & 50.0 & 0.0 & 0.0 \\
\hline Streptomycin & 25.0 & 0.0 & 0.0 \\
\hline Cefoxitin & - & - & - \\
\hline Ciprofloxacin & 50.0 & 50.0 & - \\
\hline Levofloxacin & 50.0 & 0.0 & 100.0 \\
\hline Moxifloxacin & 50.0 & 0.0 & - \\
\hline Vancomycin & 0.0 & 0.0 & 0.0 \\
\hline Tetracycline & 100.0 & 100.0 & - \\
\hline Tigecycline & 0.0 & 0.0 & 0.0 \\
\hline Linezolid & 0.0 & 0.0 & 0.0 \\
\hline Rifampicin & - & - & - \\
\hline
\end{tabular}

${ }^{\circledR}$ Percentages $=$ number of resistant antibiotics/total number of antibiotics tested

$(-)$ indicate not tested

incidence of SSI reported in neighboring Nigeria and Ghana is even higher ( $15.6 \%$ and $32.6 \%$ respectively) $[4,15]$. In our setting, it is common to use antibiotics for surgical prophylaxis [16] and one would think that the relatively low incidence of SSI can be explained by the high preoperative, intraoperative, and postoperative antibiotic use rates recorded in this study. However, according to statistical analysis, there is no significant correlation between the occurrence of SSI and the use of antibiotics. In our study, when more than two surgeons perform an operation, the patient is $70 \%$ less likely to have an infected surgical wound. Perhaps this protected some patients from acquiring an SSI, thereby reducing its incidence.

Nonetheless, similar to other studies $[4,15,17-$ 19], we identified several predictors of SSI, including ASA score $\geq 2$, male sex, preoperative admission for more than $24 \mathrm{~h}$, duration of surgery $\geq 2 \mathrm{~h}$, administration of general anaesthesia, contaminated wound type, and elevated fasting blood glucose. Worthy of note is that some of these risk factors reflect a common scenario of the severe premorbid state of many patients in Sierra Leone and thus implies that early health-seeking behavior is critical to the prevention of surgical site infections. For example, a higher preoperative ASA score is a recognized predictor of poor postoperative outcomes including the occurrence of SSI [20].

In the past 10 years, there seem to be regional differences in the bacterial isolates of postoperative wounds. On the African continent, more gram-negative bacteria than gram-positive bacteria are isolated from postoperative wounds of surgical patients [21-23]. In the Middle East, Staphylococcus aureus is a common isolate of post-operative wounds [24, 25]. According to evidence from European countries obtained from a point prevalence survey conducted by the European Center for Disease Control and Prevention (ECDC), gram-positive cocci, including $S$. aureus, are the most commonly isolated bacterial group in postoperative wounds [26]. In our study, similar to the studies from the African region [21-23], many of the isolates from postoperative wounds of patients attending surgeries in Sierra Leone are gramnegative multi-drug resistant bacilli. There are no isolates of $S$. aureus, and the Gram-positive isolates of the postoperative wounds are Enterococci, S. haemolyticus, and a rare emerging pathogen Kocuria Kristaenae. The absence of $S$. aureus including the Methicillin-Resistant strain (MRSA) in post-operative wounds may be due to the limited colonization of patients and healthcare providers by these bacteria in this setting. Thus, the use of antibiotics for surgical prophylaxis, although universal in principle, must be adjusted according to the specific context, taking into account the local antibiotic use and resistance data. As such, the synthesis of local normative data should form the foundation of country-specific guidelines on surgical prophylaxis.

Moreover, the prevalence rate of the extended-spectrum beta-lactamase-producing Enterobacteriaceae is slightly higher than previously reported in Sierra Leone (59.8\% vs. 58.0\%) [27] and the African continent as a whole $(59.2 \%$ vs. $28.0 \%)$ [28]. As the prevalence of carbapenem-resistant Enterobacteriaceae (CRE) had also increased from $1.3 \%$ in 2018 [27] to $8.4 \%$ in the present study, urgent actions are needed to set up and operationalize robust hospital-based antimicrobial stewardship programs and strengthen infection prevention and control practices. However, susceptibility to piperacillin/ tazobactam, amikacin, and carbapenems was recorded in many of the gram-negative bacteria and they could therefore be recommended for empiric use in the treatment of surgical site infections in this setting where laboratory capacity on microbiology methods is limited [16]. Nonetheless, these drugs must be used with caution to prevent the development of antibiotic resistance.

Our study has limitations and strengths. First, the assessment of the risk factors of SSI is limited to patient characteristics and some healthcare delivery activities. The study did not capture data on the influence of 
environmental factors and hand hygiene practices of the healthcare workers in the occurrence of surgical site infections. On discharge, patients were scheduled for follow-up through telephone calls, and a small group of patients did not have telephone numbers and were therefore unreachable. Some of these patients could have acquired an SSI that was not detected by the research team thus underestimating the true burden of SSI. It is also possible that patients who developed an SSI but received postoperative care in another hospital could not provide an accurate description of their postoperative wounds. Despite these inherent challenges of a typical SSI surveillance program in a resource-limited setting, we have provided more comprehensive data on SSI at different levels of surgical care in a low-income country and highlighted the huge burden of multidrug-resistant bacteria in postoperative wounds.

\section{Conclusion}

We found that the incidence of surgical site infections in two hospitals in Sierra Leone was comparable to other low- and middle-income countries but many of the postoperative wounds grew multidrug-resistant bacteria including ESBL-producing Enterobacteriaceae. Therefore, routine surveillance of surgical site infections and related antibiotic resistance is needed to guide the detection, management, and prevention in resource-limited settings.

At the same time, we highlighted several predictors of postoperative wound infections in Sierra Leone, many of which reflect that critically ill patients are receiving surgical services in these hospitals, and we thus add our voices to those who advocate for the improvement of healthseeking behaviors in low- and middle-income countries.
Funding

This work was supported in part by UK Research and Innovation as part of the Global Challenges Research Fund, Grant Number ES/P010873/1. The article processing fee was covered by the Chinese Medical Expert Group.

\section{Availability of data and materials}

The data supporting this article is available in the repository of University of Sierra Leone and will be made easily available on request to the corresponding author when required.

\section{Declarations}

\section{Ethics approval}

Ethical approval was obtained from the Sierra Leone Ethics and Scientific Review Committee of the Ministry of Health and Sanitation, Government of Sierra Leone. Written informed consent was not required for this retrospective study as it has been waived by the Sierra Leone Ethics and Scientific Review Committee of the Ministry of Health and Sanitation.

\section{Consent for publication \\ Not applicable.}

\section{Competing interests}

The authors declare that they have no competing interest.

\section{Author details}

${ }^{1}$ College of Medicine and Allied Health Sciences, University of Sierra Leone, Freetown, Sierra Leone. ${ }^{2}$ Ministry of Health and Sanitation, Government of Sierra Leone, Freetown, Sierra Leone. ${ }^{3}$ Changchun Veterinary Research Institute, Chinese Academy of Agricultural Sciences, Changchun 130000, China. ${ }^{4} 34$ Military Hospital, Freetown, Sierra Leone. ${ }^{5}$ Department of Medicine, College of Medicine, University of Ibadan, Ibadan, Nigeria. ${ }^{6}$ Department of Medicine, University College Hospital, Ibadan, Nigeria. ${ }^{7}$ Infectious Disease Research Network, Freetown, Sierra Leone. ${ }^{8}$ Department of Clinical Laboratory, The Fifth Medical Center of Chinese PLA General Hospital, Beijing 100039, China. ${ }^{9}$ World Health Organization Country Office, Freetown, Sierra Leone. ${ }^{10}$ Department of Emergency Medicine, The Fifth Medical Center of Chinese PLA General Hospital, Beijing 100039, China. ${ }^{11}$ Clinical Research Unit, Department of Medicine, Swiss Tropical and Public Health Institute, Basel, Switzerland. ${ }^{12}$ University of Basel, Basel, Switzerland. ${ }^{13}$ SolidarMed, Butha-Buthe, Lesotho. ${ }^{14}$ Centre for Multidisciplinary Research and Innovation, Abuja, Nigeria.

Received: 12 October 2021 Accepted: 9 February 2022

Published online: 21 February 2022

\begin{abstract}
Abbreviations
ASA: American Society of Anaesthesiologist; AST: Antibiotics Susceptibility Testing; CRE: Carbapenem resistant Enterobacteriacea (CRE); ECDC: European Center for Disease Control and Prevention; ESBL: Extended-spectrum betalactamase (ESBL); HAl: Healthcare associated infections; HIC: High income countries; LMIC: Low and middle income countries; SSI: Surgical site infections; WHO: World Health Organization.
\end{abstract}

\section{Acknowledgements}

We appreciate the support provided by Chinese Military Medical Expert Group at 34 Military Hospital in Sierra Leone. We are grateful to the research team members including Nurse Mariama Kamara and Nurse Emma Ngegba. We acknowledge the cooperation of the ward staff, patients and patients' relatives at the hospitals where the study was conducted.

\section{Authors' contributions}

Conceptualization: SL, LY, SS, ESS, XG, FS, OA, UB, DFJ, FS, MS, and HRW. Designed of the research: IOS, CCJ, SL, AM, CK, UB, OA, SS, XG, JSK, and NW. Laboratory work: LY, PL, JZ, YZ, and CK. Laboratory resources: XG. Data analysis: ES, SL. MNK, UB, IOS, AM, NW, and CCJ. Writing: SL, MNK, EF, ESS, UB, DFJ, FS, $M S$, and HRW. All authors read and approved the final manuscript.

\section{References}

1. World Health Organization. The second global patient safety challenge safe surgery saves lives. 2008; Available from https://www.who.int/patie ntsafety/safesurgery/knowledge_base/SSSL_Brochure_finalJun08.pdf.

2. World Health Organization. Report on the burden of endemic health care-associated infection worldwide clean care is safer care. 2011; Available at https://apps.who.int/iris/bitstream/handle/10665/80135/97892 41501507_eng.pdf.

3. Chu K, Weiser TG. Surgical site infection - the next frontier in global surgery. Lancet Infect Dis. 2018;18(5):477-8. https://doi.org/10.1016/ S1473-3099(18)30118-X.

4. Ngaroua N, Ngah JE, Bénet T, Djibrilla Y. Incidence of surgical site infections in sub-Saharan Africa: systematic review and meta-analysis. Pan Afr Med J. 2016; ISSN: 1937-8688. Available at http://www.panafrican-medjournal.com/content/article/24/171/full/.

5. World Health Organization. Global guidelines for the prevention of surgical site infection. 2018; Available at https:///C:/Users/HP\%20USER/ Downloads/9789241550475-eng.pdf.

6. Sawyer RG, et al. Surgical site infection - the next frontier in global surgery. Lancet Infect Dis. 2018;18:477-8. https://doi.org/10.1016/S14733099(18)30118-X. 
7. Badia JM, et al. Impact of surgical site infection on healthcare costs and patient outcomes : a systematic review in six European countries. J Hosp Infect. 2017;96(1):1-15. https://doi.org/10.1016/j.jhin.2017.03.004.

8. WHO. Implementation of the global action plan on antimicrobial resistance global leaders ratify major declaration to act on AMR antimicrobial resistance: tackling a threat to the health and wealth of new World Bank Research: by 2050. WHO GAP AMR Newsl. 2016;(September):1-4. Available from www.who.int/docs/default-source/searo/amr/who-amr\%2D\% 2Dgap-2-years-progress\%2D\%2Dadvocacy.pdf?sfvrsn=bcd7ae64_2.

9. Government of Sierra Leone, Ministry of Health and Sanitation. National infection prevention and control policy. Available from www.afro.who. int/publications/national-infection-prevention-and-control-guide lines-2016.

10. Di Gennaro F, Marotta C, Pisani L, Veronese N, Pisani V, Lippolis V, Pellizer G, Pizzol D, Tognon F, Bavaro DF, Oliva F, Ponte S, Nanka Bruce P, Monno $L$, Saracino A, Koroma MM, Putoto G. Maternal caesarean section infection (MACSI) in Sierra Leone: a case-control study. Epidemiol Infect. 2020;148:e40. https://doi.org/10.1017/S0950268820000370.

11. Chu K, Maine R, Trelles M. Cesarean section surgical site infections in sub-Saharan Africa: a multi-country study from Medecins Sans Frontieres. World J Surg. 2015;39(2):350-5. https://doi.org/10.1007/ s00268-014-2840-4.

12. Plachouras D, Lepape A, Suetens C. ECDC definitions and methods for the surveillance of healthcare-associated infections in intensive care units [published correction appears in Intensive Care Med. 2018 Sep 17]. Intensive Care Med. 2018;44(12):2216-8. https://doi.org/10.1007/ s00134-018-5113-0.

13. CDC/NHSN. Surveillance definition of healthcare-associated infection and criteria for specific types of infections in the acute care setting. 2013; Available at http://www.socinorte.com/wp-content/uploads/2013/03/ Criterios-de-IN-2013.pdf.

14. Saklad M. Grading of patients for surgical procedures. Anesthesiology. 1941:2:281-4.

15. Olowo-Okere A, Ibrahim YKE, Olayinka BO, Ehinmidu JO. Epidemiology of surgical site infections in Nigeria: a systematic review and meta-analysis. Niger Postgrad Med J. 2019;26(3):143-51. https://doi.org/10.4103/npmj. npmj_72 19.

16. Lakoh S, Adekanmbi O, Jiba DF, Deen GF, Gashau W, Sevalie S, Klein EY. Antibiotic use among hospitalized adult patients in a setting with limited laboratory infrastructure in Freetown Sierra Leone, 2017-2018. Int J Infect Dis. 2020;90:71-6. https://doi.org/10.1016/j.jiid.2019.10.022.

17. Li Z, Gao JR, Song L, Wang PG, Ren JA, Wu XW, Luo SM, Zeng QJ, Weng YH, Xu XJ, Yuan QZ, Zhao J, Liao NS, Mai W, Wang F, Cao H, Wang SC, Han G, Wang DR, Wang H, Zhang J, Zhang H, Zhang DM, Liao WS, Zhao WW, Li W, Cui P, Chen X, Zhang HY, Yang T, Wang L, Gao YS, Li J, Wu JJ, Zhou W, Lyu ZJ, Fang J. Risk factors for surgical site infection after emergency abdominal surgery: a multicenter cross-sectional study in China. Zhonghua Wei Chang Wai Ke Za Zhi. 2020;23(11):1043-50. https://doi.org/10. 3760/cma.j.issn.441530-20200527-00315 (Chinese).

18. Itatsu K, Yokoyama Y, Sugawara G, Kubota H, Tojima Y, Kurumiya Y, Kono $\mathrm{H}$, Yamamoto $\mathrm{H}$, Ando M, Nagino M. Incidence of and risk factors for incisional hernia after abdominal surgery. Br J Surg. 2014;101(11):1439-47. https://doi.org/10.1002/bjs.9600.

19. Winfield RD, Reese S, Bochicchio K, Mazuski JE, Bochicchio GV. Obesity and the risk for surgical site infection in abdominal surgery. Am Surg. 2016;82(4):331-6.

20. Curatolo C, Goldberg A, Maerz D, Lin HM, Shah H, Trinh M. ASA physical status assignment by non-anesthesia providers: do surgeons consistently downgrade the ASA score preoperatively? J Clin Anesth. 2017;38:123-8. https://doi.org/10.1016/j.jclinane.2017.02.002.

21. Dessie W, Mulugeta G, Fentaw S, Mihret A, Hassen M, Abebe E. Pattern of bacterial pathogens and their susceptibility isolated from surgical site infections at selected referral hospitals, Addis Ababa, Ethiopia. Int J Microbiol. 2016;2016:2418902. https://doi.org/10.1155/2016/2418902.

22. Raouf M, Ghazal T, Kassem M, Agamya A, Amer A. Surveillance of surgicalsite infections and antimicrobial resistance patterns in a tertiary hospital in Alexandria, Egypt. J Infect Dev Ctries. 2020;14(3):277-83. https://doi. org/10.3855/jidc.12124

23. Agyepong N, Govinden U, Owusu-Ofori A, Essack SY. Multidrug-resistant gram-negative bacterial infections in a teaching hospital in Ghana.
Antimicrob Resist Infect Control. 2018;7:37. https://doi.org/10.1186/ s13756-018-0324-2.

24. El-Saed A, Balkhy HH, Alshamrani MM, Aljohani S, Alsaedi A, Al Nasser W, El Gammal A, Almohrij SA, Alyousef Z, Almunif S, Alzahrani M. High contribution and impact of resistant gram negative pathogens causing surgical site infections at a multi-hospital healthcare system in Saudi Arabia, 2007-2016. BMC Infect Dis. 2020;20(1):275. https://doi.org/10.1186/ s12879-020-4939-6

25. Nejad ZS, Darabzadeh Z, Mazloomirad F, Khoramrooz SS, Ghatee MA, Sisakht SN, Esfandiari H, Sharifi A, Nia FS. Antimicrobial susceptibility pattern in the bacteria isolated from surgical site infection: emphasis on Staphylococcus aureus; Yasuj City, Southwest Iran. Clin Lab. 2021;67(2). https://doi.org/10.7754/Clin.Lab.2020.200530.

26. Zarb P, Coignard B, Griskeviciene J, Muller A, Vankerckhoven V, Weist K. National Contact Points for the ECDC pilot point prevalence survey, Hospital Contact Points for the ECDC pilot point prevalence survey. The European Centre for Disease Prevention and Control (ECDC) pilot point prevalence survey of healthcare-associated infections and antimicrobial use. Euro Surveill. 2012;17(46). Available at https://www.eurosurveillance. org/content/10.2807/ese.17.46.20316-en?crawler=true.

27. Lakoh S, Li L, Sevalie S, Guo X, Adekanmbi O, Yang G, Adebayo O, Yi L, Coker JM, Wang S, Wang T, Sun W, Habib AG, Klein EY. Antibiotic resistance in patients with clinical features of healthcare-associated infections in an urban tertiary hospital in Sierra Leone: a cross-sectional study. Antimicrob Resist Infect Control. 2020;9(1):38. https://doi.org/10.1186/ s13756-020-0701-5.

28. Tansarli GS, Poulikakos P, Kapaskelis A, Falagas ME. Proportion of extended-spectrum $\beta$-lactamase (ESBL)-producing isolates among enterobacteriaceae in Africa: evaluation of the evidence-systematic review. J Antimicrob Chemother. 2014;69(5):1177-84. https://doi.org/10. 1093/jac/dkt500.

\section{Publisher's Note}

Springer Nature remains neutral with regard to jurisdictional claims in published maps and institutional affiliations.

Ready to submit your research? Choose BMC and benefit from:

- fast, convenient online submission

- thorough peer review by experienced researchers in your field

- rapid publication on acceptance

- support for research data, including large and complex data types

- gold Open Access which fosters wider collaboration and increased citations

- maximum visibility for your research: over 100M website views per year

At BMC, research is always in progress.

Learn more biomedcentral.com/submissions 